\title{
Assessment of Workplace Hazard and Safety Performance of the Construction Industry
}

\author{
${ }^{1}$ Lateef. Owolabi Mudashiru, ${ }^{* 2}$ Emmanuel Olayimika Sangotayo, ${ }^{3}$ Olayinka Olawuni, \\ Ladoke Akintola University of Technology Ogbomoso, Mechanical Engineering Dept, \\ 11. \\ *Corresponding author: eosangotayo@lautech.edu.ng
}

\section{Abstract}

The Construction industry contributes significantly to the socio-economic improvement of any country. Notwithstanding its significance, the Construction industry has been categorized as one of the greatest dangerous industries across the world. This investigation appraised the workplace hazard and safety performance of the Construction industry in the Asaba, Delta region of Nigeria. Qualitative and Quantitative study survey technique was deployed. The collected data was analyzed to define the safety performance of the industry. T-test and ANOVA statistics were used to institute the significant effect on safety administration application in the industry. This work reveals that the proprietor and member of staff have appropriate consciousness of job-related healthiness and security then there are policies and systems in place to make the workplace safe. Workers are not exposed significantly at $95 \%$ to security and health risks in the workstation, and the workforces are not contributing significantly at 5\% significant level to making a workstation secure for employees. Workers should be contributing to making a workstation safe for workers for it is the function of staff activities and skills; the manager's activities and practices. The outcomes of the finding point out that an improved welfare and exposure involvement of all personnel in the construction industry would bring positive changes in the employee's attitude and better-quality of the site throughput in Nigeria.

Keywords: Hazard and Safety Performance, Construction Industry

DOI: $10.7176 /$ IEL/11-2-05

Publication date:September $30^{\text {th }} 2021$

\subsection{Introduction}

The construction industry has frequently been condemned for its inadequate performance in safety and health. The principle of safety in construction is for a reservation the life expectancy of workers and material goods. The construction industry is the core of social and economic growth in all nations of the biosphere (Agwu, $\&$ Olele, 2014). Nevertheless, the construction industry contributed only about $1.98 \%$ of the overall Gross Domestic Product (GDP) to the Nigerian budget in 2009, its significance and roles in the growth of the economy of any country cannot ever be doubtful. Traditionally, construction remains an industry where labours may sense that taking risks is a part of the work and may worry about what their peers think of those who take extra precautions. The reality is that construction workers are more exposed toworkplace injuries because of the inherent dangers of a job that often involves working with large machinery and power tools (Cesarini et al. 2013).

Safety performance on construction sites is usually measured using lagging indicators such as accidents and not by using leading indicators such as safe work behaviors. Customarily, safety in construction sites has always been determined bythe level of execution of safety measures and guidelines, and danger control pieces of machinery. Safety culture is the precedence concern of people working in a society; though, emphasizing that society can only be recognized with safety culture after it has advanced to a certain phase (Adeogun and Okafor, 2013). The construction industry adds to the improvement and development of any state. Undertakings of the industry are energetic to the socio-economic growth objectives of the country by providing work, accommodation, and infrastructure. The construction industry gives an average of over $3 \%$ to the annual gross domestic product and an average of about one-third of the total fixed capital investment in Nigeria (Oladinrin et al.2012) Though, the construction industry has been categorized amongst the utmost hazardous industries in the globe.

In many countries such as Great Britain, mortalities in the construction area cover $38 \%$ and are documented to be the maximum as related to other subdivisions such as $29 \%$ for agriculture, $12 \%$ kor waste, and $15 \%$ for both transport and storage and manufacturing. (Idoro, 2011; Windapo and Jegede, 2013). The 
industry alone yields $30 \%$ of the entire deadly engineeringcalamities across the European Union (EU), nonetheless, it employs only $10 \%$ of the employed populace (McKenzie et al. 999.). In the United States of America (USA), the construction industry accounts for $22 \%$ of totally mortal misfortunes, in Japan 30\%$40 \%$ and the United Kingdom (UK) $25 \%$ of the global manufacturing mishaps (Bomel, 2001 \& Hassan et al.2007).

Brown (1996) noted how safety is governed in the construction industry that has not been transformed over the years substantially. In the manufacturing division, the operational environment and the work techniques continue essentially unaffected from day-to-day. These consist of deficiencies in the current universal level of safety and health education, general indifference and contentment towards safety and health problems, deficiency of quality and commitment of site organization, deficiency of sufficient possessions assigned to safety and health. Prior researchers have stressed that no dependable data on misfortune cases exist in the Nigerian construction industry for contractors neither report mishaps properly nor preserve appropriate registers on calamities. (Agwu \& Olele, 2014).

Overemphasis at location level on construction goals to the understandable loss of worthy safe working practices, failure of teadministration to set sufficient assets into safety implementation, and the deficiency of emphasis on the portion of some constructionexperts in safety and health subjects. Cariel (1991) added that only with suitable administration commitment, establishment, and planning, it is promising to attain safer working environs that are also budget effective. The comprehension of the expenses of accidents and human suffering have transported changes in the assertiveness of administration and employees to safety. The implication of guaranteeing safety in the work atmosphere is primarily supported by diverse educations as the work location is uncovered to inherent hazards and risk issues that exact undesirable effects on the organization's total performance. Subsequently, the construction industry introduces one of the most dangerous industries. There is an extensive deviation in economic organizations, occupational constructions, working situations, work atmosphere, and the health rank of workforces in diverse areas of the biosphere, in diverse nations, and diverse regions of the economy. Hence the modernization of the construction productiveness is not even throughout the biosphere. Nevertheless, construction productiveness plays an energetic role in improving the economy of any nation, specifically an unindustrialized nation. It offers the structure required for other areas of the economy to be an embellishment.

Coble and Haupt (1999) had presented that the construction industry echoes the level of economic expansion within the nation. The construction zone all over faces difficulties and trials. Conversely, in unindustrialized nations, these complications and trials are present together with an overall level of socio-economic trauma and a lesser production rate when likened to advanced nations (Ofori, 2000). However, it is largely understood that construction productiveness is a decent source of occupation at numerous levels of expertise, from broad labour to semi-skilled, skilled, and expert labour force. The deficiency of research and development, shortage of trade and safety training, customer displeasure, and the uninterruptedly growing construction expenses are other key areas that influence the construction industry

Construction within emerging nations frequently fails to meet the requirements of contemporary modest industries in the marketplace and hardly offers the paramount value for customers and taxpayers (Datta, 2000). Moreover, this segment reveals pitiable performance in respect of quality administration and safety principles due to the lack of any severe safety and construction regulations. The unfortunate quality organization and safety philosophy registers in construction plans within unindustrialized nations were attributed to the great proportion of minor companies and the great number of entrepreneurial workers; the diversity and relatively short life of construction places; and the extraordinary turnover of workers; and the huge amount of periodic and refugee workers. In an unindustrialized nation, there are no training plans for workforce and personnel; so, no orientation for the fresh workforce is accompanied; dangers are not pointed out, and no safety conferences are held. Workforces are expected to acquire from their faults and practice. (Kartam, 1997; Kartam and Bouz, 1998 \& Kartam, et al., 2000)

In embracing diverse methods to quality administration and safety beliefs in technologically advanced and emerging nations, two core changes can be recognized. The first is the presence of regulation and its effective execution; the second is risk consciousness. In advanced nations, numerous safety acts and regulations occur and are executed efficiently. Designated safety officers uphold hazard consciousness with the aid of steady safety training meetings. In unindustrialized nations, but, safety guidelines scarcely exist at all; and when they do, they 
are unsuitable, unproductive, obsolete, and built on circumstances that triumphed while the nation was still being occupied. Furthermore, the supervisory expert is regularly very feeble in executing guidelines efficiently, and work risks are either not observed at all, or observed to be less hazardous than they are (Larcher and Sohail, 1999; Hinze et al., 1999).

Ugwu et al. (2021) assessed of Safety Performance of the NigerianConstruction Industry and stated that the topmost supervision is committed to the application of occupational health and safety administration hence there would be improved safety practices and reduced frequency of calamities. Izobo-Martins et al (2018) presented safety in Construction: reducing the bodily Stresses onEmployees in Nigeria and it was that an enhanced safety attitude and ergonomics of the bodily demands on all labours in the construction industry would bring variations in the workforce attitude and better-quality of the site throughput in Nigeria. This study examines the operative execution of a safety administration system in the construction industry to ensure the best performance and determine the consequence of safety administration on project performance in a construction firm

\subsection{RESEARCH METHODOLOGY}

\section{Research Design}

The survey was conducted with a Construction Company in Asaba, Delta state. It comprised structured questionnaires that were distributed to over 70 construction workers, contractors, and consultant organizations. A total of 55 members of staff were available to complete the survey, 37 responses were received which makes a 67 percent return rate. A series of interviews with both safety managers and quality managers were held during the same period.

\section{Questionnaire Structure:}

The questionnaire consists of 4 sections and is planned to discover the workplace health and safety at Aba, Abia State Nigeria. The participants were requested to share their views about the workstation and how it upsets health and safety by taking this survey. The questions on the hazards confronted on the job and the occupational health and safety (OHS) guidelines and procedures in place to defend the employee. The survey is unsigned and the answers assisted to determine areas that may need enhancement to better defend the safety and health of employees.

\section{Section 1: Workplace exposures}

This segment requests about the types of health and safety menaces workers might be exposed to in the occupation. The best defines how often participants do the stated job or are wide-opened to the stated situation.

\section{Section 2: Workplace guidelines and measures}

This section explains the varieties of policies and systems in place to make the workstation safe. The best defines how much participants approve or differ with the declaration.

\section{Section 3: Occupational healthiness and safety consciousness}

This section discovers worker's consciousness of occupational healthiness and security, the best defines how much partaker approves or differs from the declaration.

\section{Section 4: Contribution in occupational healthiness and security}

This unit discovers worker's ability to request about, and contribute to, well-being and protection at work, the best defines how much participants support or differ from the declaration.

\section{Hypotheses}

Four (4) hypotheses were itemized on the hazards encountered on the work and the job-related healthiness and security strategies and measures in place to defend the employee

\section{Hypothesis 1}

Ho: There are no significant healthiness and safety threats employee is exposed to at the workplace.

H1: There is significant healthiness and safety threats employee is exposed to at workplace.

\section{Hypothesis 2}

Ho: There are no significant plans and schemes in place to make the workplace harmless.

H1: There are significant plans and schemes in place to make the workplace harmless 


\section{Hypothesis 3}

Ho: There is no significant consciousness of job-related healthiness and security such as dangers, the moralities, and duties of both personnel and managers).

H1: There is significant workers' consciousness to job-related healthiness and security such as dangers, the moralities, and duties of both personnel and managers).

\section{Hypothesis 4}

Ho: There is no significant involvement of workers in making a workstation harmless for staff depends on both employees' activities and aptitudes and the employer's activities and practices

H1: There are significant involvement of workers in making a workstation harmless for staff depends on both employees' activities and aptitudes and the employer's activities and practices. The hypotheses were tested using t-test and ANOVA analysis at a 95\% confidence limit.

\section{T-test analysis}

The t-test is used for testing hypotheses concerning the mean of a small trial occupied population when the standard deviation of the populace is not identified. The t-test defines if there is a significant difference between the means of the two groups. T-test principles estimate values that are compared with standard values, when the null and alternative hypotheses are recognized, the null hypothesis is either accepted or rejected.

The $\mathrm{T}$-test is related to the $\mathrm{z}$-test and $\mathrm{f}$-test but the t-test is typically executed where the trial size, $\mathrm{n}$ is insignificant $(\mathrm{n} \leq 30)$. T-value was determined using Eqn (1) (Kothari, 1990)

$$
\mathrm{t}=\frac{\bar{x}+\mu}{\frac{\sigma^{2}}{\sqrt{n}}}
$$

where $\overline{\mathbf{x}}$ is the mean of the trial, and $\boldsymbol{\mu}$ is the assumed mean, $\boldsymbol{\sigma}$ is the standard deviation, and $\mathbf{n}$ is the number of observations.

T-test for the difference in mean was determined using Eqn (2) (Kothari, 1990)

$$
\mathrm{t}=\frac{\bar{x}_{1}-\bar{x}_{2}}{\sqrt{\frac{\left(n_{1}-1\right) \sigma_{1}^{2}+\left(n_{2}-1\right) \sigma_{2}^{2}}{n_{1}+n_{2}-2}} \times \sqrt{\frac{1}{n_{1}}+\frac{1}{n_{2}}}}
$$

where $\overline{\mathbf{x}} \mathbf{1}$ and $\overline{\mathbf{x}} \mathbf{2}$ are the mean of two samples and $\boldsymbol{\sigma} \mathbf{1}$ and $\boldsymbol{\sigma 2}$ is the standard deviation of two samples, and $\mathbf{n} \mathbf{1}$ and $\mathbf{n} \mathbf{2}$ are the numbers of observation of two samples.

\section{Analysis of Variance. ANOVA}

ANOVA utilizes the F-test for statistical significance. This allows for the contrast of many means at once for the error is estimated for the entire set of comparisons rather than for each two-way contrast. The F-test evaluates the difference in each group mean from the global group alteration. If the change within groups is smaller than the change between groups, the F-test gets a higher F-value, and consequently, a superior chance that the discrepancy observed is real and not owing to possibility.

The null hypothesis $\left(\mathrm{H}_{0}\right)$ of ANOVA is that there is no alteration among set means. The alternate hypothesis $\left(\mathrm{H}_{\mathrm{a}}\right)$ is that at least one group differs considerably from the general mean of the dependent variable.

P-value is the possibility of finding a test statistic that is at least as severe as the actual calculated value if the null hypothesis is true. A universal cut-off value of the $p$-value is 0.05 , if the calculated $p$-value of a test statistic is less than 0.05 that the null hypothesis is discarded.

\section{The hypothesis test}

The essential ANOVA analysis consists of a succession of calculations as presented in Table 1.0. (Kothari, 1990, Kothari, 2002). 
Table 1.0 Two-way ANOVA table for Block Randomized Experiment (Kothari, 2002)

\begin{tabular}{|c|c|c|c|c|}
\hline $\begin{array}{l}\text { Source of } \\
\text { variation }\end{array}$ & df & $\begin{array}{l}\text { Sums of } \\
\text { squares }\end{array}$ & Mean square & $\mathbf{F}$ \\
\hline Factor A & $k-1$ & SSA & $M S A=\frac{5 S A}{k-1}$ & $F_{A}=\frac{M S A}{M S E}$ \\
\hline Factor B & $l-1$ & SSB & $M S B=\frac{S S B}{l-\mathbf{1}}$ & $F_{B}=\frac{M S B}{M S E}$ \\
\hline Interaction $\mathrm{AB}$ & $\begin{array}{c}(k-1)(l- \\
1)\end{array}$ & SSAB & $M S A B=\frac{5 S A B}{(k-1)(l-1)}$ & $F_{A B}=\frac{M S A B}{M S E}$ \\
\hline Error & $k l(m-1)$ & SSE & $M S E=\frac{S S E}{k l(m-1)}$ & \\
\hline Total & $k \operatorname{lm}-1$ & SSTo & & \\
\hline
\end{tabular}

The $\mathrm{df}$ is the degrees of freedom for the independent variable. The Sum Square is the addition of squares between the set means. The Mean Square represents the summation of squares, calculated by dividing the summation of squares by the degrees of freedom. The F-value is the ratio of the mean square of each independent variable to the mean square of the residuals. F-value is calculated using Eqn(3)

$$
F=\frac{M S \text { (Factor })}{M S(\text { Error })}
$$

Mean squares (MS) is the design for the mean square for the factor in Eqn (4):

$$
M S \text { Factor }=\frac{S S \text { (Factor })}{D F(\text { Factor })}
$$

The design for the mean square for error is obtained using $\operatorname{Eqn}(5)$

$$
M S \text { Error }=\frac{S S \text { (Error })}{D F(\text { Error })}
$$

Where MS is Mean Square, SS is Sum of Squares and DF is Degrees of Freedom

\subsection{RESULTS AND DISCUSSION}

A total of 55 members of staff were available to complete the survey, 37 responses were received, a 67 percent return rate. The reason for failing to complete the questionnaire was mainly related to lack of time, although it was clear that some senior members of staff thought the questionnaire impinged on the management function.

\section{Data Analysis}

The purpose of each question is stated while carrying out the analysis and the result is demonstrated using appropriate charts and statistical tests. Questions are grouped as some questions are relevant to each other, making the analysis of responses to those questions more sensible. Assessment of workplace safety and health study was conducted at, Aba, Abia State Nigeria. 


\section{Workstation Hazards}

Figure 1 presents how often personnel exposes to workstation menaces with durations of daily, weekly, and monthly assessments.

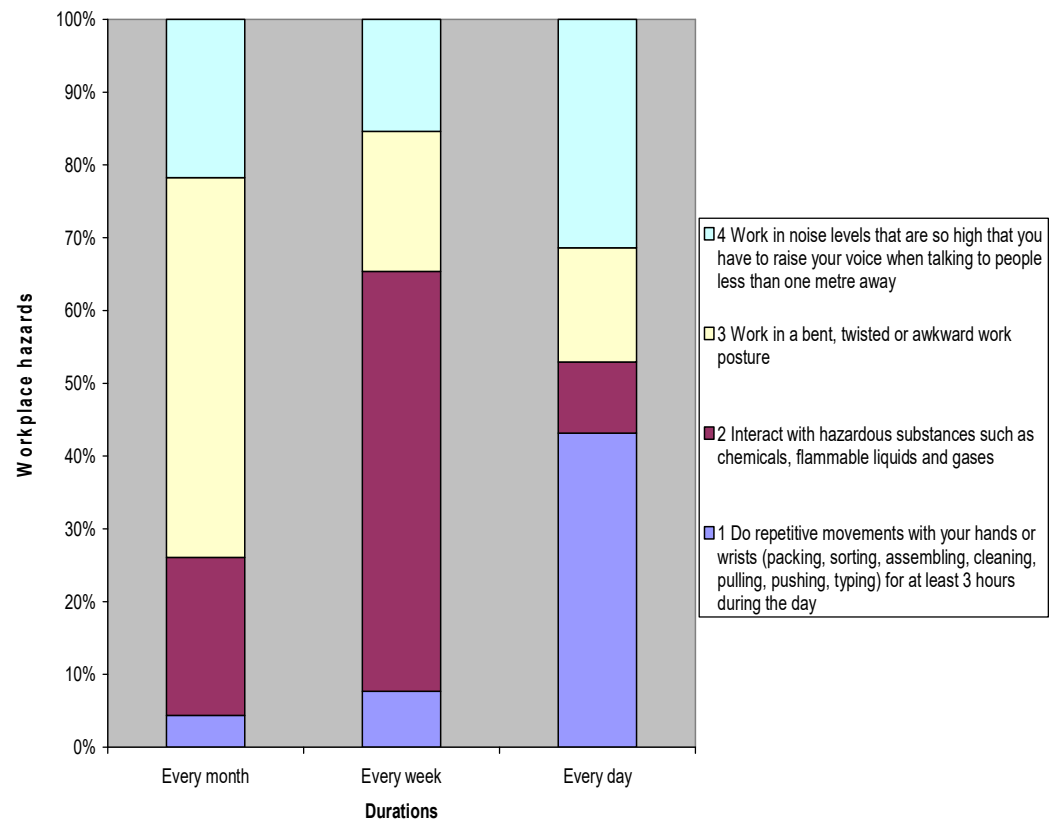

Figure 1.0: Graph of workstation hazards versus duration

Daily assessment, $4 \%$ of workers do recurring movements with the hands or wrists, $22 \%$ of staff relate with risky substances such as gases, combustible liquids, and chemicals, 52\% of personnel work in a bent, twisted, or awkward work position and $22 \%$ of workers work in high-level noise environment that require the worker to raise voice when speaking to people less than one meter away

Weekly assessment, $8 \%$ of workers do recurring movements with the hands or wrists, $52 \%$ of staffs relate with risky substances such as gases, combustible liquids, and chemicals, $19 \%$ of personnel work in a bent, twisted, or awkward work position and $15 \%$ of workers work in high-level noise environment that require the worker to raise voice when speaking to people less than one meter away

Monthly assessment, $43 \%$ of workers do recurring movements with the hands or wrists, $10 \%$ of staff relate with risky substances such as gases, combustible liquids, and chemicals, $16 \%$ of personnel work in a bent, twisted, or awkward work position and $31 \%$ of workers work in high-level noise environment that require the worker to raise voice when speaking to people less than one meter away

ANOVA analysis was conducted to examine whether the workers are exposed to health and safety menaces in the workstation.

\section{Hypothesis 1}

Ho: There are no significant health and security threats at the workplace, and H1: There are significant health and security threats at the workplace.

Table 2.0 presents the summary of ANOVA analysis at a $5 \%$ significance level, which decides to admit or discard the hypotheses 
Table 2.0: One Way ANOVA Analysis for Workplace Menaces with Durations

\begin{tabular}{|c|c|c|c|c|c|c|}
\hline Source of Variation & $S S$ & $d f$ & $M S$ & $F$ & P-value & $F$ crit \\
\hline Between Groups & 118.1667 & 2 & 59.08333 & 1.552555 & 0.263471 & 4.256495 \\
\hline Within Groups & 342.5 & 9 & 38.05556 & & & \\
\hline Total & 460.6667 & 11 & & & & \\
\hline
\end{tabular}

Table 1.0 ANOVA analysis reveals that $\mathrm{F}$ value $=1.552555$ is less than $\mathrm{F}$-Critical $=4.256495$, and P-value is 0.2634 is greater than P-Critical of 0.05 . It indicates that Ho is accepted while Hi is rejected, therefore ANOVA confirms that employees are not significantly exposed to health and security threats in the workstation or occupation

\section{Job-related Healthiness and Security Perspective}

Figure 2 presents the respondents' views on job-related healthiness and security perspective $14 \%$ of workers strongly agreed to point out to administration whenever a risk is observed at the workstation, $50 \%$ of employees strongly agreed to stop the task if an unsafe condition arises and management will address the condition, and $36 \%$ of staff strongly settled that there is adequate time to complete work unharmed

$54 \%$ of workers agreed to point out to administration whenever a risk is observed at the workstation, $21 \%$ of employees agreed to stop the task if an unsafe condition arises and management will address the condition, and $25 \%$ of staff settled that there is adequate time to complete work unharmed.

$32 \%$ of workers disagreed to point out to administration whenever a risk is observed at the workstation, $26 \%$ of employees disagreed to stop the task if an unsafe condition arises and management will not address the condition, and $42 \%$ of staff disagreed that there is adequate time to complete work unharmed

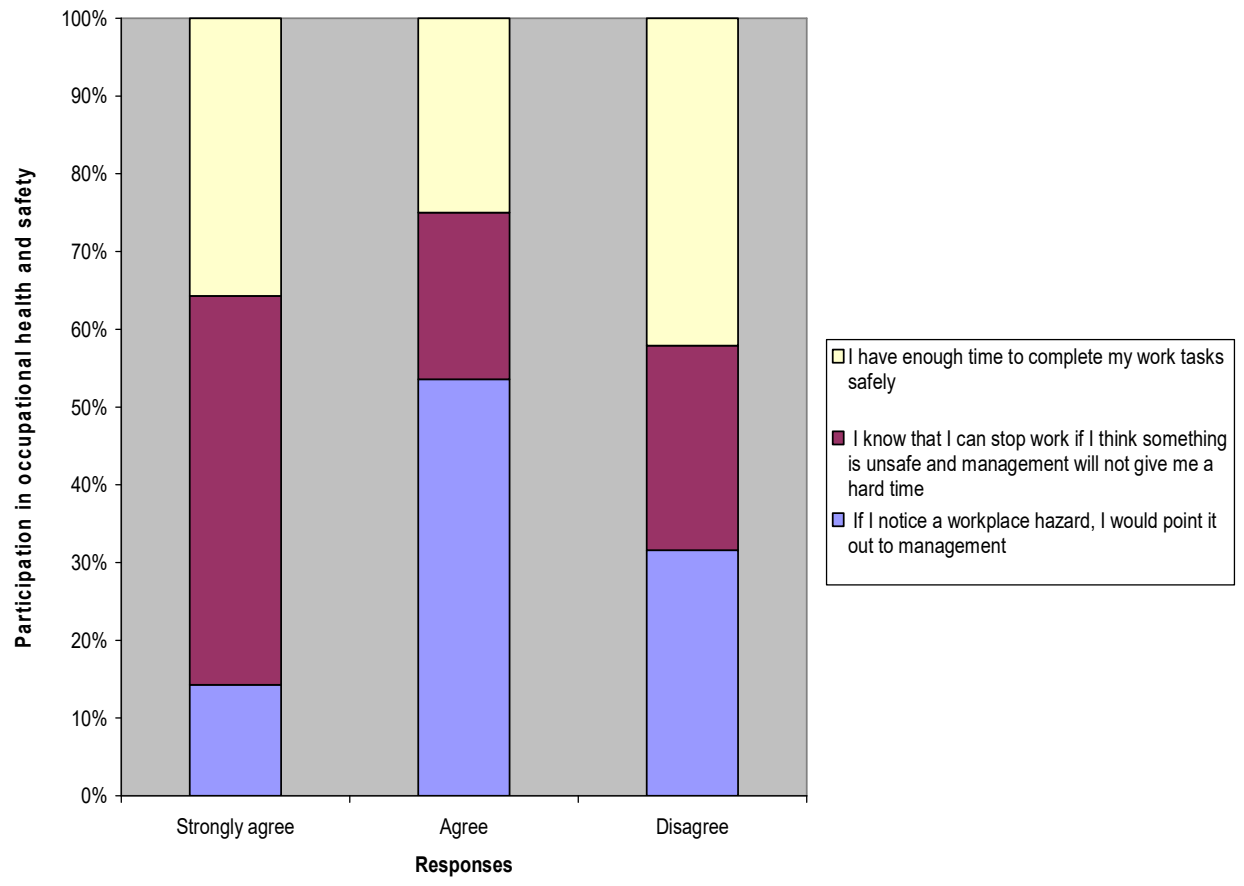

Figure 2.0: Plot of involvement in job-related healthiness and security versus workers' views

ANOVA analysis was conducted to further study the involvement of workers in making a workstation harmless for staff depends on both employees' activities and aptitudes and the employer's activities and practices 


\section{Hypothesis 2}

Ho: There is no significant involvement of workers in making a workstation harmless and H1: There is significant involvement of workers in making a workstation harmless

Table 3.0 presents the summary of ANOVA analysis at a $5 \%$ significance level, which decides to admit or discard the hypotheses

Table 3.0: One Way ANOVA Analysis for the Involvement of Workers in Making a Workstation Harmless

\begin{tabular}{lllllll}
\hline Source of Variation & $S S$ & $d f$ & $M S$ & $F$ & P-value & $F$ crit \\
\hline Between Groups & 18 & 2 & 9 & 0.519231 & 0.6194704 & 5.14325285 \\
Within Groups & 104 & 6 & 17.33333 & & & \\
Total & 122 & 8 & & & \\
\hline
\end{tabular}

Table 3.0 ANOVA analysis reveals that $\mathrm{F}$ value $=0.519231$ is less than F-Critical $=4.256495$, and P-value is 0.6194704 is greater than P-Critical of 0.05. It indicates that Ho is accepted while Hi is rejected, therefore ANOVA confirms that employees are not significantly involved in making a workstation harmless for staff which depends on both employees' activities and aptitudes and the employer's activities and practices.

\section{Workplace Guidelines and Measures}

This section inquiries the varieties of policies and systems in place to make the workstation secure. The findings revealed that $81 \%$ of workers robustly agreed that there are plans and schemes in place to make the workplace harmless and 19\% of workers approved that there are plans and schemes in place to make the place of work risk-free. T-test analysis was performed to examine the significance of the different policies and systems in place to make the workstation risk-free.

\section{Hypothesis 3}

Ho: There are no significant plans and schemes in place to make the workplace harmless, and H1: There are significant plans and schemes in place to make the workplace harmless

Table 4.0 presents the summary of T-test analysis at a $5 \%$ significance level, which decides to admit or discard the hypotheses.

Table 4.0: T-Test Analysis for Policies and Systems in Place for Two-Sample Unequal Variances

\begin{tabular}{lll}
\hline & Variable 1 & Variable 2 \\
\hline Mean & 20.28571429 & 4.714285714 \\
Variance & 2.904761905 & 2.904761905 \\
Observations & 7 & 7 \\
Hypothesized Mean Difference & 0 & \\
df & 12 & \\
t Stat & 17.09256381 & \\
$\mathrm{P}(\mathrm{T}<=\mathrm{t})$ one-tail & $4.32781 \mathrm{E}-10$ & \\
$\mathrm{t}$ Critical one-tail & 1.782287548 & \\
$\mathrm{P}(\mathrm{T}<=\mathrm{t})$ two-tail & $8.65561 \mathrm{E}-10$ & \\
$\mathrm{t}$ Critical two-tail & 2.178812827 & \\
\hline
\end{tabular}

Table 4.0 t-test analysis reveals that $\mathrm{t}$ Stat $=17.09256381$ is greater than both $\mathrm{t}$-Critical one-tail $=1.782287548$ and $\mathrm{t}$-Critical two-tail $=2.178812827$, P-values are less than P-Critical of 0.05 , then Hi is accepted but Ho is rejected, 
therefore t-test confirms that the proprietor and worker have significant plans and schemes in place to make the workplace harmless

\section{Job-Related Healthiness and Safety Consciousness}

This section describes worker's consciousness of occupational health and security such as risk, human rights, and duties of both workforces and managers. The findings revealed that $26 \%$ of workers robustly agreed that there is a worker's consciousness of occupational health and security such as threat, and duties of both workforces and managers, and 74\% of workers approved that there is a worker's consciousness of occupational health and security such as the civil rights, and duties of both workforces and managers. T-test analysis was executed to examine the significance of the worker's consciousness to occupational health and security

\section{Hypothesis 4}

Ho: There is no significant workers consciousness to job-related health and security and H1: There is significant workers' consciousness to job-related health and security

Table 5.0 presents the summary of T-test analysis at a $5 \%$ significance level, which decides to admit or discard hypothesis 4 .

Table 5.0 T-test Analysis For Worker's Consciousness To Occupational Health and security for Two-Sample Unequal Variances

\begin{tabular}{lll}
\hline & Variable 1 & Variable 2 \\
\hline Mean & 6.333333333 & 18.33333333 \\
Variance & 30.26666667 & 29.86666667 \\
Observations & 6 & 6 \\
Hypothesized Mean Difference & 0 & \\
df & 10 & \\
t Stat & -3.790523836 & \\
$\mathrm{P}(\mathrm{T}<=\mathrm{t})$ one-tail & 0.001770172 & \\
t Critical one-tail & 1.812461102 & \\
$\mathrm{P}(\mathrm{T}<=\mathrm{t})$ two-tail & 0.003540345 & \\
$\mathrm{t} \mathrm{Critical} \mathrm{two-tail}$ & 2.228138842 & \\
\hline
\end{tabular}

Table 5.0 t-test analysis reveals that $\mathrm{Stat}=3.790523836$ is greater than both $\mathrm{t}$-Critical one-tail $=1.812461102$ and $\mathrm{t}$-Critical two-tail $=2.228138842$, P-values $(0.001770172 / 0.003540345)$ are less than P-Critical of 0.05 , then Hi is accepted but Ho is rejected, therefore t-test confirms that the owner and worker have significant proper consciousness to job-related healthiness and security such as dangers, the moralities, and duties of both personnel and managers.

\section{Conclusions}

The Construction industry contributes significantly to the socio-economic improvement of any country. This work has appraised the workplace hazard and safety performance of the Construction industry in the Asaba, Delta region of Nigeria. The following conclusions are drawn after the analysis of the Workplace health and safety survey at Aba, Abia State Nigeria that the manager and member of staff have appropriate consciousness of job-related health and security such as risks, the moralities, and duties of both staff and proprietors, then there are documentations and systems in place to make the workstation secure. Personnel is not exposed to health and safety risks in their workstation or occupation, hence the workforces are not sharing in making a workshop safe for staff which depends on both member of staff activities and skills and the company's schedules 
and practices. Staff should be partaking in making a workstation safer for personnel which depends on both member of staff activities and skills and the company's schedules and practices. The outcomes of the finding point out that an improved welfare and exposure involvement of all personnel in the construction industry would bring positive changes in the employee's attitude and better-quality of the site throughput in Nigeria.

\section{References}

Adeogun, B., \& Okafor, C. C. (2013). Occupational Health, Safety and Environment (HSE) Trend in Nigeria. International Journal of Environmental Science, Management andEngineering Research Vol. 2 (1), JanFeb., pp. 24-29.

Adeogun, B., \& Okafor, C. C. (2013). Occupational Health, Safety and Environment (HSE) Trend in Nigeria. International Journal of Environmental Science, Management andEngineering Research Vol. 2 (1), JanFeb., pp. 24-29.

Agwu, M. O., \& Olele, H. E. (2014). Fatalities in the Nigerian Construction Industry: A Case of Poor Safety Culture. British Journal of Economics, Management \& Trade 4(3): pp431-452.

Bomel A. (2001). Improving health and safety in construction. Phase 1: Data Collection, Review, and Structuring. Contract Research Report. 387.

Brown, (1996) "Total integration of safety professional into project management," in Proceedings of the 1st International Conference of CIB Working Commission W99, pp. 137-144, Lisbon, Portugal,

Cariel J. C. R. (1991 )"Safety management in operations," in Proceedings of the 1st International Conference on Health, Safety \& Environmental, pp. 421-428,

Cesarini, G., Hall, G., \& Kupiec, M. (2013). Building a Proactive Safety Culture in the Construction Industry. Philadelphia, PA 19106, United States: ACE Construction.

Coble, R.J. and Haupt, T.C. (1999) - Construction Safety in Developing Countries: Implementation of Safety and Health on Construction Sitesll. Proceedings of the 2nd International. Conference of International Council for Research and Innovation Construction (CIB) Working Commission W99. Honolulu, pp. 903-908.

Datta, M. (2000) Challenges Facing the Construction Industry in Developing Countries. Proceedings of the 2nd International Conference on Construction in Developing

Hassan CC, Basha OJ, Hanafi WW. (2007) Perception of building construction workerstowards safety, health, and environment. Journal of Engineering Science andTechnology. Vol.2 (3):271-279.

Hinze, J., Coble, R., and Elliott, B. (1999) Integrating Construction Worker Protection into Project Design. Proceeding of the Second International Conference of CIB Working Commission W99, Implementation of Safety and Health on Construction Sites, Honolulu, Hawaii, pp. 24-27.

Idoro GI. (2011) Comparing occupational healthand safety (OHS) management efforts and performance of Nigerian construction contractors. Journal of Construction inDeveloping Countries. 16 (2):151- 173.

Izobo-Martins O.O., Ayo-Vaughan E.O, Badejo O.O, Ekhaese E.N., Elenwo C and Nwakudu I, (2018,) Safety in Construction: Reducing the Physical Demands on Workers in Nigeria. International Journal of Civil Engineering and Technology, 9(9), pp. 215-221.

Kartam, N. (1997) Integrating safety and health performance into construction CPM. Journal of Construction Engineering and Management, Vol 123, No. 2, p. 121-126.

Kartam, N.A. and Bouz, R.G. (1998) Fatalities and Injuries in Kuwait Construction Industry. Accident Analysis and Prevention, 30 (6), pp. 805-814.

Kartam, N.A., Flood, I. and Koushki, P. (2000) Construction safety in Kuwait: issues, procedures, problems, and recommendations, Safety Science, pp. 36163-36184

Kothari C.R. (2002), "Research methodology: Methods and techniques", Vishwa Prakashan, New Delhi, 2nd Edition, pp 277-278, 300-302, 376-378

Kothari R. (1990) Research Methodology. Vishwa Prakasan. India.

Larcher, P. and Sohail, M. (1999) Review of Safety in Construction and Operation for the WS\&S Sector-A Literature Review: Part I. UK: Loughbourough University.

McKenzie J, Gibb AGF, and Bouchlaghem N.M. (1999).Communication of health and safety in the design phase. Implementation of safety and health on construction sites. Proceedings of the 2nd International Conference of International Council for Research and Innovation in Building and Construction (CIB) Working Commission W99. Honolulu, Hawaii, 24-27.

Ofori, G. (2000), Challenges of construction industries in developing countries: lessons from various countries, Proceedings of the 2 nd international conference of the CIB TG29 on Construction in Developing Countries: Challenges facing the construction industry in developing countries 15-17 November 2000, Gaborone, Botswana, pp.1-3. 
Oladinrin O, Ogunsemi D, and Aje I.O. (2012) Role of the construction sector in economic growth: empirical evidence from Nigeria. FUTY Journal of the Environment.;7: pp.50-60. DOI:https://doi.org/10.4314/fje.v7i1.4

Ugwu T. P., Nwaichi E. O. and Patrick C.E. (2021) Evaluation of Safety Performance of NigerianConstruction Industry - A Case Study of the Niger Delta Region, Journal of Scientific Research \& Reports, 27(2): 94103,

Turner J. R. and Muller R. (2003). “On the nature of the project as a temporary organization,” International Journal of ProjectManagement, vol. 21, no. 1, pp. 1-8,

Windapo AO, Jegede OP. (2013) A study of health, safety, and environment (HSE) practices of Nigerian construction companies. The Professional Builder.;4 (1):92-103. 